\title{
Effects of the hydroxyl radical scavenger, dimethylthiourea, on peripheral nerve tissue perfusion, conduction velocity and nociception in experimental diabetes
}

\author{
N. E. Cameron, Z. Tuck, L.McCabe, M. A. Cotter \\ Department of Biomedical Sciences, Institute of Medical Sciences, University of Aberdeen, Scotland, UK
}

\section{Abstract}

Aims/hypothesis. Increased oxidative stress has been linked to diabetic neurovascular complications, which are reduced by antioxidants. Our aim was to assess the contribution of hydroxyl radicals to early neuropathic changes by examining the effects of treatment with the specific scavenger, dimethylthiourea, on nerve function and neural tissue blood flow in diabetic rats.

Methods. Diabetes was induced by streptozotocin. Measurements comprised sciatic nerve motor and saphenous nerve sensory conduction velocity. Responses to noxious mechanical and thermal stimuli were estimated by Randall-Sellito and Hargreaves tests respectively. Sciatic nerve and superior cervical ganglion blood flow were measured by hydrogen clearance microelectrode polarography.

Results. Eight weeks of diabetes reduced motor and sensory conduction velocity by $19.9 \%$ and $15.7 \%$ respectively, and these were completely corrected by 2 weeks of dimethylthiourea treatment. The $\mathrm{ED}_{50}$ for motor conduction was $9 \mathrm{mg} \cdot \mathrm{kg}^{-1} \cdot \mathrm{day}^{-1}$. Mechanical and thermal nociceptive sensitivities were $18.9 \%$ and $25.0 \%$ increased by diabetes, respectively, indicating hyperalgesia which was $70 \%$ reduced by dimethylthiourea. Sciatic endoneurial and superior cervical ganglion blood flows were $51.2 \%$ and $52.4 \%$ reduced by diabetes and there was an approximately $80 \%$ improvement with treatment.

Conclusion/interpretation. Hydroxyl radicals seem to make a major contribution to neuropathy and vasculopathy in diabetic rats. Treatment with the hydroxyl scavenger, dimethylthiourea, was highly effective. The data suggest that the development of potent hydroxyl radical scavengers suitable for use in man could markedly enhance the potential therapeutic value of an antioxidant approach to the treatment of diabetic neuropathy and vascular disease. [Diabetologia (2001) 44: 1161-1169]

Keywords Neuropathy, pain, nerve conduction, blood flow, autonomic ganglion, oxidative stress, hydroxyl radical, dimethylthiourea, diabetic rat.
Oxidative stress contributes to the neural and vascular complications of diabetes [1,2]. For nerve, antioxidant protection is impaired; glutathione content is

Received: 13 April 2001 and in revised form: 28 May 2001

Corresponding author: Dr. Norman E.Cameron, Diabetic Complications Lab, Department of Biomedical Sciences, Institute of Medical Sciences, University of Aberdeen, Foresterhill, Aberdeen AB25 2ZD, Scotland, UK. E-mail: n.e.cameron $@$ abdn.ac.uk

Abbreviations: DMTU, dimethylthiourea; NCV, nerve conduction velocity; ROS, reactive oxygen species; SCG, superior cervical ganglion diminished and lipid peroxidation markers are increased [2, 3]. Vascular endothelium is also vulnerable to oxidative stress, including the nitric oxide system $[1,4]$. Treatment with free radical scavengers increases nerve conduction velocity (NCV), blood flow and regenerative capacity [3,5-9] and protects endothelial function [10-12]. The vasa nervorum and the nitric oxide system in nerve complications is important in that antioxidant effects on function are largely abolished by nitric oxide synthase inhibitor co-treatment in experimental models [13]. It has been noted, however, that extremely high doses of natural scavengers such as vitamins $\mathrm{E}$ or $\mathrm{C}$ are re- 
quired to correct nerve and vascular dysfunction [6, $10]$ possibly because they do not optimally scavenge the most important reactive oxygen species (ROS), or because they do not distribute well in the appropriate cellular or body compartment.

Several potential sources of ROS have been suggested; superoxide could be generated by endothelial $\mathrm{NAD}(\mathrm{P}) \mathrm{H}$ oxidase, nitric oxide synthase, mitochondrial respiratory chain inefficiency, or xanthine oxidase mechanisms $[1,14]$. Autoxidation reactions of glucose and its metabolites and advanced glycation could be important sources of ROS [15]. The highly reactive hydroxyl radical can be produced from superoxide and hydrogen peroxide by the Haber-Weiss reaction and from peroxide by the transition metal catalysed Fenton reaction. Superoxide readily reacts with nitric oxide to give peroxynitrite, which decomposes to liberate hydroxyl radicals [16]. For vascular and nerve complications it is not clear whether the superoxide itself and its interaction with nitric oxide is the important pathophysiological step or whether a peroxide or hydroxyl radical mechanism is more relevant. Studies with metal chelators have emphasised the importance of the latter process for neurovascular dysfunction [9, 17-19], however, interpretation is complicated because other potential transition metal catalysed mechanisms also enhance the glycoxidation process $[20,21]$. Therefore, to further delineate the ROS mechanisms responsible for neurovascular dysfunction, the effect of treatment with the hydroxyl radical scavenger, dimethylthiourea (DMTU), on measures of large and small nerve fibre function and peripheral nervous tissue perfusion were examined in diabetic rats.

\section{Materials and methods}

Experiments were carried out in accordance with regulations specified by the United Kingdom 'Animal Procedures Act, 1986' and the National Institutes of Health 'Principles of Laboratory Animal Care, 1985 revised version'.

Experimental groups and diabetes induction. Male SpragueDawley rats (Aberdeen University colony), 19 weeks old at the start of the study were used. Diabetes, induced by intraperitoneal streptozotocin (Astra-Zeneca Pharmaceuticals, Macclesfield, Cheshire, UK) at 40 to $45 \mathrm{mg} / \mathrm{kg}$ freshly dissolved in sterile $0.9 \%$ saline solution, was verified $24 \mathrm{~h}$ later by estimating hyperglycaemia and glycosuria (Visidex II and Diastix; Ames, Slough, UK). Blood samples were taken from the tail vein to measure plasma glucose (GOD-Perid method; Boehringer Mannheim, Mannheim, Germany) just before final experiments.

Three sets of experimental groups were used. The first study was preventive, diabetes duration being 4 weeks, and measurements were made of NCV. The second was an intervention study, where diabetes duration was 8 weeks, treatment being given for the final 2 weeks. Measurements were on sciatic nerve blood flow, and on nerve conduction including the dose-response relationship for sciatic motor NCV. In the third investigation, also an intervention study, measurement of responses to noxious mechanical and thermal stimulation were made to assess function of pain small-fibre systems before and after 2 weeks of treatment, followed by measurement of superior cervical ganglion (SCG) blood flow.

Dimethylthiourea dissolved in sterile saline (Sigma, Poole, Dorset, UK) was injected daily intraperitoneally, for all studies except the dose-response determination, the dose was set at $100 \mathrm{mg} / \mathrm{kg}$.

Sciatic nerve and superior cervical ganglion blood flow. Rats were anaesthetised with thiobutabarbital (Astra-Zeneca; $50-100 \mathrm{mg} / \mathrm{kg}$ ), by intraperitoneal injection. The trachea was cannulated for artificial ventilation. A cannula in the right carotid artery was used to monitor mean systemic blood pressure. Core temperature was monitored and regulated at 37 to $38^{\circ} \mathrm{C}$, using a rectal probe and radiant heat.

Blood flow was estimated by microelectrode polarography and hydrogen clearance as described [22]. For peripheral nerve recordings, the sciatic nerve was exposed between sciatic notch and knee. For ganglion recordings, the left SCG was located in the vicinity of the carotid bifurcation. In both cases, the skin around the incision was used to form a pool that was filled with paraffin oil maintained at 35 to $37^{\circ} \mathrm{C}$ by radiant heat during measurements. A glass-insulated platinum microelectrode was inserted into the appropriate neural structure and polarised at $0.24 \mathrm{~V}$ according to a subcutaneous reference electrode. $10 \% \mathrm{H}_{2}$ was added to the inspired gas, the proportions of $\mathrm{O}_{2}$ and $\mathrm{N}_{2}$ were adjusted to $20 \%$ and $70 \%$ respectively. When the $\mathrm{H}_{2}$ current recorded by the electrode had stabilised, indicating equilibrium with arterial blood, the $\mathrm{H}_{2}$ supply was shut off and $\mathrm{N}_{2}$ delivery was increased appropriately. The $\mathrm{H}_{2}$ clearance curve was recorded until baseline, the latter was defined as no systematic decline in electrode current over 1 min for SCG or $5 \mathrm{~min}$ for sciatic nerve recordings. This procedure was then repeated at another site. Clearance curves were digitised and monoexponential or biexponential curves were fitted offline by computer using non-linear regression, the Marquardt algorithm and the least squares method for optimising goodness-of-fit (Prism, Graphpad, San Diego, Calif., USA). The slow exponent was considered to reflect nutritive flow [22].

Nerve function tests. Rats were anaesthetised with urethane (1-1.5 g/kg, dissolved in saline) by intraperitoneal injection for the preventive study, or with thiobutabarbital in the reversal study when blood flow was measured. The sciatic nerve was exposed between sciatic notch and knee and motor NCV was measured as described previously [23] in the nerve branch to the tibialis anterior muscle, which is representative of the whole sciatic nerve in terms of susceptibility to diabetes and treatment effects. Saphenous nerve sensory NCV was measured between the groin and calf. Rectal and near nerve temperatures were monitored and regulated between 36.5 and $37.5^{\circ} \mathrm{C}$ with radiant heat.

Nociceptive thresholds for mechanical stimulation were measured by the Randall-Sellito test [24] and latencies for withdrawal reflexes to noxious thermal stimulation of the foot were estimated by the Hargreaves plantar test [25] using commercially available equipment (Ugo-Basile, Comerio, Italy). Briefly, tests were carried out in a constant room temperature at the same time each day, and rats were given a 3-day period for familiarisation with handling, the environment and equipment, and the measurement procedure. Mechanical pressure thresholds were then estimated twice a day for each foot over a 3-day period before DMTU treatment commenced. After 12 days of treatment, thresholds were again determined over 3 days. Data from the 3 pre-treatment and 3 end-of-treatment 
days were averaged to give pressure threshold values. Each day after mechanical testing, rats were placed in the thermal testing apparatus, which consisted of a perspex enclosure with a glass base, in which they were free to move. After $30 \mathrm{~min}$ acclimatisation, a constant power infrared stimulus was focussed through the glass base onto the sole of the foot and the latency for reflex foot withdrawal which was automatically recorded by a photoelectric monitor. For each session four measurements were obtained, two from each foot, the average was taken as the final withdrawal latency. As with the mechanical estimates, there was a 3 -day run-in period, followed by 3 days predrug and end-of-drug testing.

Statistical analysis. Results are expressed as means \pm SEM. Data were subjected to Bartlett's test for homogeneity of variances, followed by log transformation if necessary before oneway ANOVA. Where significance $(p<0.05)$ was reached, between group differences were established using the StudentNeuman-Keuls or Bonferroni multiple comparison tests. If variances were not homogenous, data were analysed by appropriate non-parametric tests, such as Kruskal-Wallis one-way ANOVA followed by Dunn's multiple comparison test. Within-group serial comparisons were made using paired Student's $t$ tests.

\section{Results}

Body weights and blood glucose concentrations are given in Table 1. Diabetes caused an approximately sixfold increase in plasma glucose and approximately $19 \%$ and $25 \%$ weight loss after 4 and 8 weeks, respectively. These parameters were not affected by DMTU treatment.

Diabetes of 4 and 8 weeks duration caused $22.5 \pm 1.1 \%$ and $19.8 \pm 0.8 \%$ reductions $(p<0.001)$ in sciatic motor NCV (Fig.1 A, C), respectively. Saphenous sensory NCV (Fig. 1 B, D) also showed $17.6 \pm 1.3 \%$ and $15.7 \pm 0.9 \%$ deficits $(p<0.001)$. High-dose $(100 \mathrm{mg} / \mathrm{kg})$ DMTU treatment completely prevented the development of the motor NCV defect over 4 weeks $(p<0.001)$ and reduced the sensory deficit by $91.8 \pm 12.7 \%(p<0.001)$. In the intervention experiment, both motor and sensory NCV reductions were completely corrected $(p<0.001)$ by DMTU treatment. Dose-response intervention studies on sciatic motor NCV (Fig. 2) showed a relatively high sensitivity to DMTU, the lowest dose used ( $3 \mathrm{mg} / \mathrm{kg}$ ) giv-
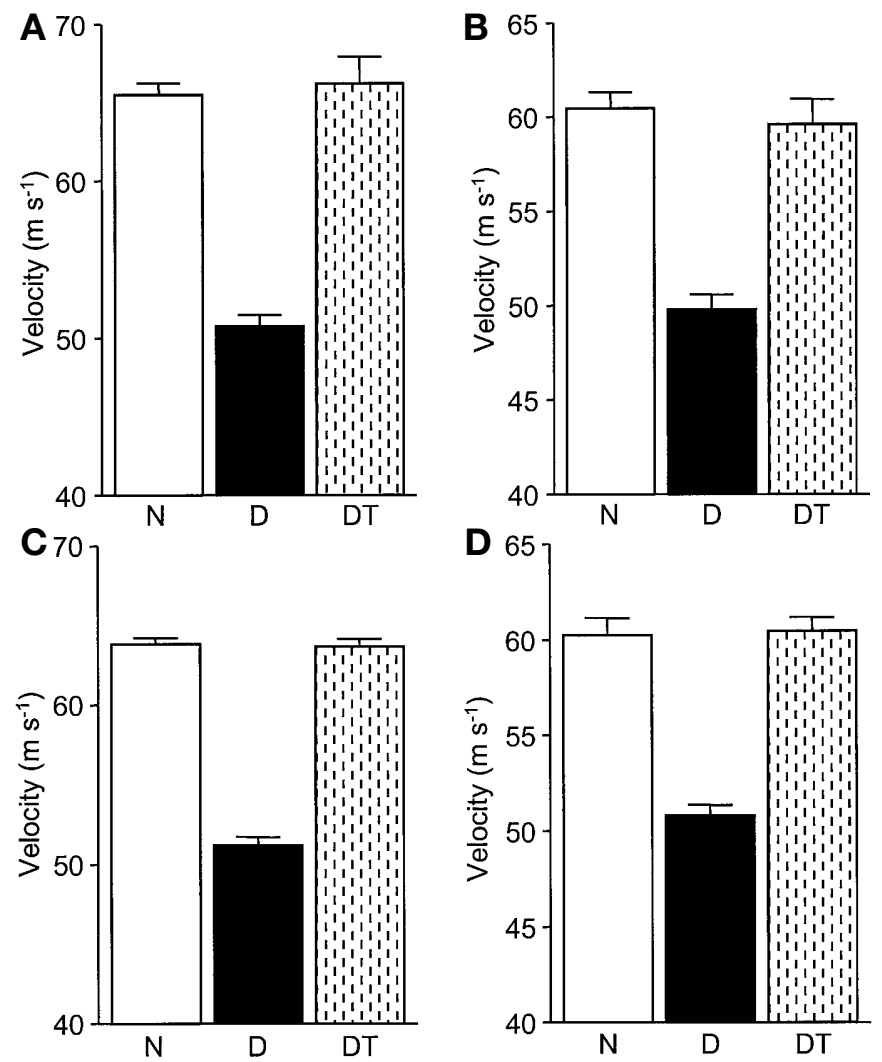

Fig. 1(A-D). Effects of diabetes and dimethylthiourea treatment on sciatic motor and saphenous sensory conduction velocity. Preventive study: A sciatic motor, B saphenous sensory $\mathrm{NCV}$, diabetes duration 4 weeks. Intervention study: $\mathbf{C}$ sciatic motor, $\mathbf{D}$ saphenous sensory NCV, diabetes duration 8 weeks, treatment for the last 2 weeks. $\mathrm{N}$, nondiabetic groups $(n=10)$; $\mathrm{D}$, untreated diabetic groups $(n=10)$; DT, dimethylthioureatreated diabetic groups, $100 \mathrm{mg} \cdot \mathrm{kg}^{-1} \cdot$ day $^{-1}, n=6$ and $n=9$ for preventive and intervention studies respectively. Data are means + SEM

ing $22.3 \pm 6.3 \%$ amelioration $(p<0.05)$. The $\log$ $\mathrm{ED}_{50}$ was $0.955 \pm 0.009$, corresponding to a dose of approximately $9 \mathrm{mg} / \mathrm{kg}$.

Thresholds to noxious mechanical stimulation of the foot (Fig. 3A) were $18.9 \pm 2.2 \%$ reduced $(p<0.01)$ by diabetes, indicating hyperalgesia. Two weeks of DMTU treatment increased thresholds $(p=0.024)$ to a value not significantly different from

Table 1. Body weights and plasma glucose concentrations ${ }^{\mathrm{a}}$

\begin{tabular}{llllr}
\hline Group & $n$ & \multicolumn{2}{l}{ Body weight $(\mathrm{g})$} & Plasma glucose $\left(\mathrm{mmol} \mathrm{l}^{-1}\right)$ \\
\cline { 2 - 4 } & & Start & End & $6.4 \pm 0.3$ \\
\hline $\begin{array}{l}\text { Non-diabetic } \\
\text { Diabetic control }\end{array}$ & 28 & $456 \pm 3$ & - & $41.8 \pm 2.7$ \\
4 week & 10 & $495 \pm 10$ & $395 \pm 16$ & $41.4 \pm 2.6$ \\
8 week & 18 & $465 \pm 6$ & $340 \pm 8$ & $34.5 \pm 1.1$ \\
Diabetic + DMTU & 6 & $492 \pm 17$ & $409 \pm 24$ & $38.7 \pm 0.8$ \\
4 week prevention & 49 & $474 \pm 3$ & $368 \pm 7$ & \\
8 week reversal & &
\end{tabular}

\footnotetext{
${ }^{a}$ Data are means \pm SEM
} 


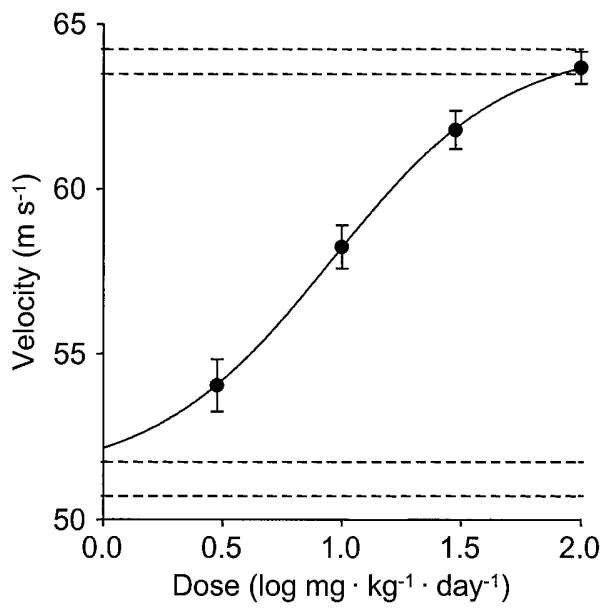

Fig. 2. Dose-response curve for correction of a sciatic motor conduction velocity deficit by dimethylthiourea in diabetic rats. After 6 weeks of untreated diabetes, groups of rats $(n=7-8)$ were given dimethylthiourea treatment at doses of $3,10,30$ or $100 \mathrm{mg} \cdot \mathrm{kg}^{-1} \cdot \mathrm{day}^{-1}$ for 2 weeks. Data are means \pm SEM. Dashed lines, envelopes of \pm SEM as reference values for nondiabetic (upper) and diabetic controls (lower); data taken from groups in Fig. 1C

that of the non-diabetic group, representing $61.9 \pm 18.0 \%$ correction of the diabetic deficit. The latency for foot withdrawal from noxious thermal stimulation (Fig. 3B) was $25.0 \pm 4.1 \%$ reduced by diabetes $(p<0.01)$, suggesting thermal hyperalgesia, which was partially $(73.1 \pm 13.6 \%, p=0.002)$ corrected by DMTU treatment.

Sciatic endoneurial nutritive blood flow (Fig. 4A) was $51.2 \pm 3.5 \%$ decreased $(p<0.001)$ by 8 weeks of diabetes, which was largely $(86.4 \pm 9.7 \%, p<0.001)$ corrected by 2 weeks DMTU treatment. Systemic perfusion pressure during the hydrogen clearance measurements (Fig. 4B) was approximately $19 \%$ reduced by diabetes, regardless of DMTU treatment $(p<0.01)$. As peripheral nerve does not show pressure autoregulation, the perfusion results are expressed as nutritive vascular conductance (Fig. 4C). The diabetic conductance deficit was $38.0 \pm 3.8 \%$ $(p<0.001)$; DMTU treatment caused conductance values to be in the top half of the non-diabetic range.

Hydrogen clearance curves for peripheral nerve are usually composed of two simultaneously recorded components. A fast component arises from clearance by large vessels (non-nutritive arterial, venous and arteriovenous flow) and a slow component results from nutritive (capillary) clearance. Composite (total endoneurial) flow (Fig. 5A), was $62.5 \pm 5.5 \%$ decreased and conductance (Fig. 5B) was $52.3 \pm 6.5 \%$ reduced in the diabetic group $(p<0.01)$. DMTU treatment restored flow and conductance into the nondiabetic range $(p<0.01)$. There was no difference between the proportion of hydrogen clearance carried by the nutritive flow component, an index of changes in flow pattern (Fig. 5C).
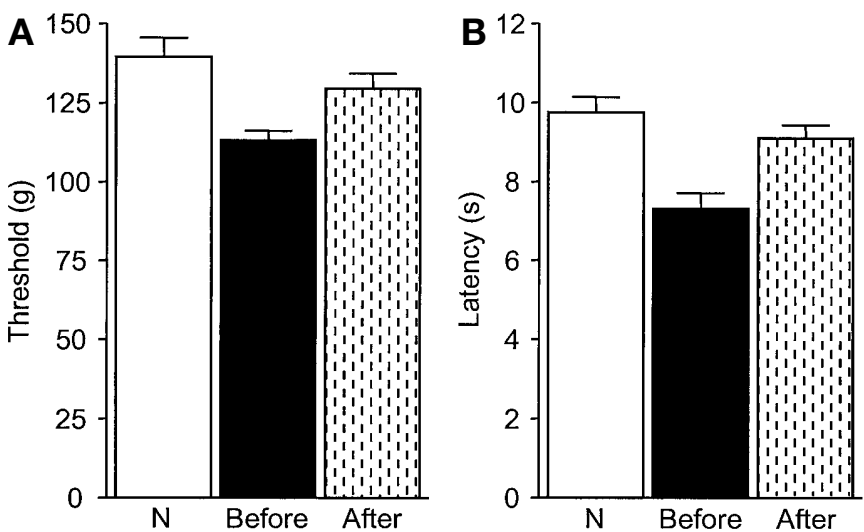

Fig.3 (A, B). Effects of diabetes and dimethylthiourea treatment on responses to noxious stimuli. A mechanical stimulation thresholds for foot withdrawal, using the Randall-Sellito test; B latency for foot withdrawal from thermal stimulation using the Hargreaves plantar test. N, nondiabetic control group $(n=8)$; diabetic group $(n=9)$ at 6 weeks, Before or After 2 weeks of DMTU treatment $\left(100 \mathrm{mg} \cdot \mathrm{kg}^{-1} \cdot \mathrm{day}^{-1}\right)$. Data are means + SEM

There was a $52.4 \pm 3.5 \%$ deficit $(p<0.001)$ in SCG blood flow (Fig. 6A) after 8 weeks of diabetes, which was $76.4 \pm 9.1 \%$ corrected $(p<0.001)$ by DMTU treatment. Systemic blood pressure during the flow recordings did not differ significantly between experimental groups (Fig. 6B).

\section{Discussion}

The data show that DMTU had marked preventive and corrective effects on motor and sensory NCV deficits in diabetic rats. This is in line with the actions of other ROS scavengers, such as vitamin E, probucol analogues, acetyl cysteine and lipoic acid [3, 5-8, 13, 26]. The dose-response data showed a particularly high efficacy for DMTU, compared to previously studied ROS scavengers for which similar data are available. Thus, the $\mathrm{ED}_{50}$ for DMTU was approximately $9 \mathrm{mg} / \mathrm{kg}$, compared with $360 \mathrm{mg} / \mathrm{kg}$ for vitamin E. Vitamin C was maximally effective at a dose of $150 \mathrm{mg} / \mathrm{kg}$, although this only gave $35 \%$ protection against diabetic NCV deficits [6]. The probucol analogue, BM150639, which is 8 times more effective as an antioxidant in vivo than probucol itself, had an $\mathrm{ED}_{50}$ of approximately $40 \mathrm{mg} / \mathrm{kg}$ [13], as did lipoic acid which is both a ROS scavenger and transition metal chelator [26]. Dimethylthiourea is a relatively specific scavenger of hydroxyl radicals, although it will also react with hydrogen peroxide. Thus, the extremely high efficacy of DMTU emphasises the importance of a hydroxyl radical and/or peroxide mechanism in diabetic nerve dysfunction.

The effects of DMTU were apparent for measures of both large fibre (NCV) and small fibre function. In the latter case, both mechanical and thermal hyperal- 
A

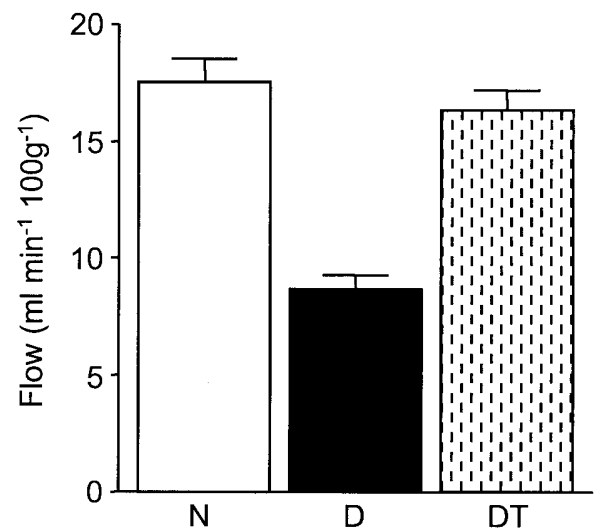

B

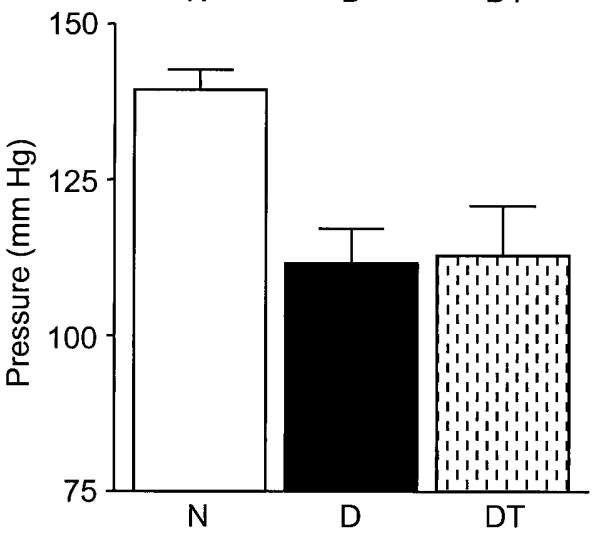

C

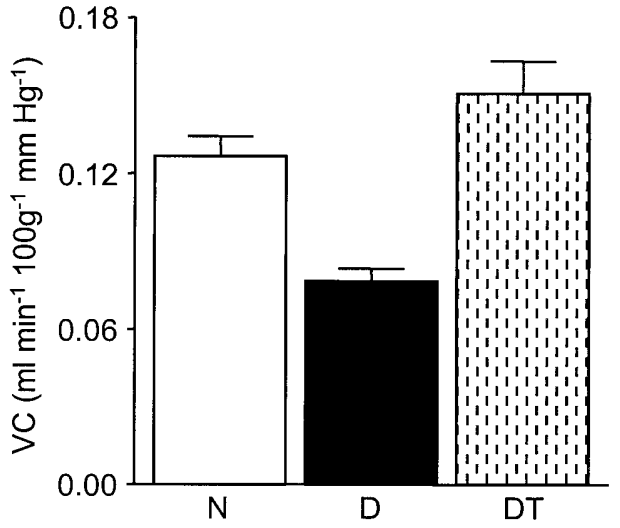

Fig. 4(A-C). Effects of diabetes and dimethylthiourea treatment on sciatic endoneurial nutritive perfusion. A endoneurial blood flow; B mean systemic arterial pressure; $\mathbf{C}$ endoneurial vascular conductance (VC). N, nondiabetic group $(n=10) ; \mathrm{D}$, 8 week untreated diabetic group $(n=10)$; DT, treated diabetic group $(n=9)$ untreated for 6 weeks then given dimethylthiourea $\left(100 \mathrm{mg} \cdot \mathrm{kg}^{-1} \cdot \mathrm{day}^{-1}\right)$ for 2 weeks. Data are means + SEM

gesia were corrected, although the methodology used does not allow discrimination between peripheral and central DMTU actions on these nociceptive systems. Mechanical hyperalgesia has been noted in several studies on different experimental hyperglycaemic models [27, 28]. There is less agreement about changes in response to thermal stimulation in diabetic rats. Thus, for streptozotocin-induced diabetes in young rats, the tail flick test showed thermal hyposensitivity [29]. However, in our investigation, in some other studies using streptozotocin-diabetic
A

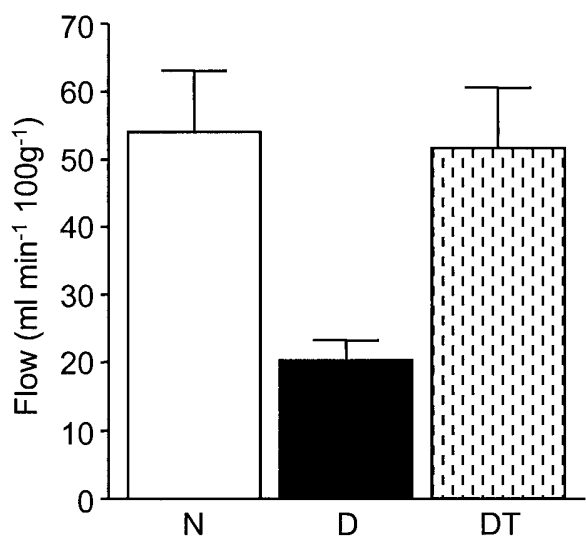

B

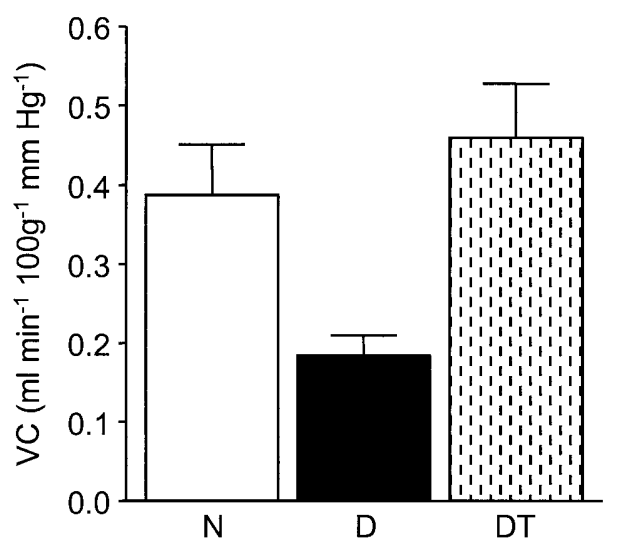

C

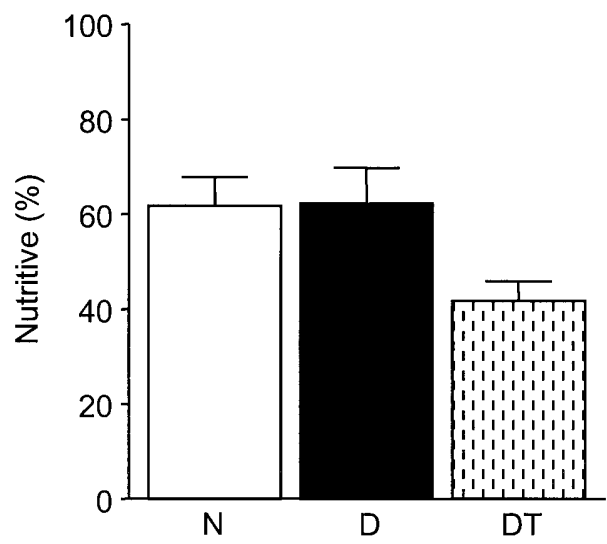

Fig.5(A-C). Effects of diabetes and dimethylthiourea treatment on total sciatic endoneurial perfusion. A Total endoneurial blood flow; $\mathbf{B}$ vascular conductance (VC); $\mathbf{C}$ proportion of hydrogen clearance by the nutritive flow component. Groups as for Fig. 4. Data are means + SEM

rats, and in a model of Type II diabetes, thermal hyperalgesia was apparent [30, 31].

Partial correction of thermal and mechanical hyperalgesia by DMTU indicates the involvement of peroxide and/or hydroxyl radicals. The mechanism is uncertain; there have not been any reports of ROS participation in the actual transduction process for mechanical or thermal nociceptors. Increased protein kinase $\mathrm{C}$ activity has, however, been implicated in the changes in both large fibre and small autonomic fibre function in diabetes $[32,33]$. In addition, electrophys- 

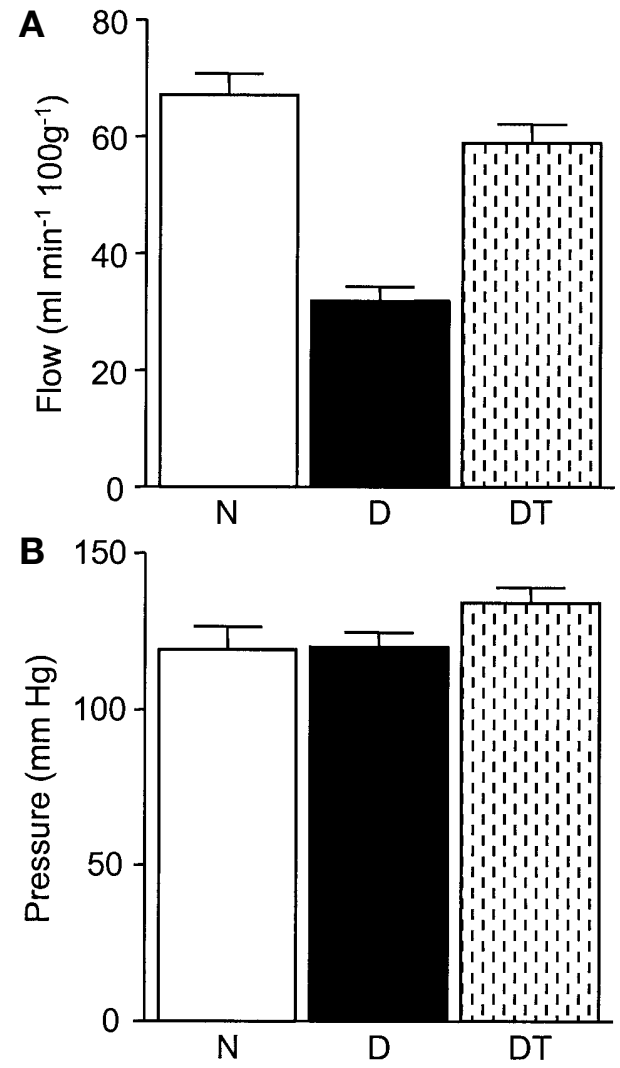

Fig.6(A, B). Effects of diabetes and dimethylthiourea treatment on superior cervical ganglion nutritive perfusion. A Blood flow; B mean systemic blood pressure. N, Nondiabetic group $(n=8) ; \mathrm{D}, 8$-week untreated diabetic group $(n=8)$; DT, treated diabetic group $(n=9)$ untreated for 6 weeks, then given dimethylthiourea $\left(100 \mathrm{mg} \cdot \mathrm{kg}^{-1} \cdot \mathrm{day}^{-1}\right)$ for 2 weeks. Data are means + SEM

iological studies of mechanosensitive skin nociceptor afferents showed altered responses to stimulation in diabetic rats, which were acutely corrected by a protein kinase $\mathrm{C}$ inhibitor [34]. Moreover, the importance of protein kinase $\mathrm{C} \gamma$ to neuropathic pain has been demonstrated in knockout mice [35]. This could relate to oxidative stress because the latter activates protein kinase $\mathrm{C}$ in diabetes and ischaemia-reperfusion models [36, 37]. Vascular protein kinase $\mathrm{C}$ is also stimulated in experimental galactosaemia [38]; a model of increased oxidative stress that exhibits hyperalgesia and reduced NCV in the absence of changes in insulin concentrations or glucose homeostasis $[9,27,39,40]$. Thus, the data emphasise the importance of oxidative stress, by a mechanism that could involve protein kinase $\mathrm{C}$ activation, in the altered nociceptive responses of diabetic rats. This agrees with clinical trial data from diabetic patients, where treatment with the antioxidant, lipoic acid, caused improvements in symptomatic neuropathy, including pain perception [41]. The question remains as to whether antioxidant effects are mediated by direct nerve fibre effects, or via improvements in nerve per- fusion, or both. Impaired blood flow seems to contribute to noxious stimulus hypersensitivity because allodynia is reduced by vasodilator treatment in diabetic rats, which parallels effects on large fibre NCV $[42,43]$.

Dimethylthiourea treatment had marked effects on sciatic endoneurial nutritive blood flow, in agreement with other ROS scavenger studies [3, 5-7, 13, 26], the magnitude was sufficient to account for the motor and sensory NCV improvements [1]. Total endoneurial perfusion, which includes nutritive, large vessel and ateriovenous shunt flow, was also completely corrected by DMTU, indicating a general effect on vasa nervorum without changes in flow pattern. This correlates with the actions of ROS scavengers such as probucol [5], vitamin E [6], lipoic acid [26], and the extracellular metal chelator, hydroxyethyl starch-deferoxamine [19]. The mechanisms underlying these vascular changes are not known in detail. Experiments on aorta and basilar artery show that DMTU prevents the development of reduced nitric oxide-mediated endothelium-dependent relaxation in diabetic rats [44, 45], also found in treatment using other scavengers or metal chelators [10-12, 18, 46]. As vasa nervorum shows a diabetic nitric oxide deficit [47, 48], it is likely that a similar situation applies to DMTU action in this vascular bed, which could be responsible for improvements in nerve blood flow. Hydroxyl radicals result from the decomposition of peroxynitrite, the product of reaction between nitric oxide and superoxide [16]. Dimethylthiourea should not interfere with peroxynitrite production; therefore, the data suggest that it is the hydroxyl radicals themselves that are the important pathophysiological mediator. Dimethylthiourea can also scavenge hydrogen peroxide; however, this is not likely for the vascular results because hydrogen peroxide can both increase endothelial nitric oxide synthase expression and cause vasodilation $[49,50]$. In aorta from diabetic rats, catalase preincubation reduced endothelium-dependent relaxation to acetylcholine [51]. Therefore, if peroxide scavenging were an important action of DMTU under these experimental conditions then reduced vasodilation and decreased nerve blood flow might be expected. Thus, in conjunction with the marked efficacy of DMTU in correcting NCV deficits, the data emphasise the importance of hydroxyl radicals in neurovascular dysfunction in diabetes. Aside from peroxynitrite, a potentially important source of hydroxyl radicals comes from transition metal catalysed Fenton reactions. Metal chelator studies show that this effect could be important for vascular and nerve function [17-19, 46]. As with DMTU, relatively low chelator doses are required for high neurovascular efficacy [17] and the effects of clearing free transition metal ions from the vascular space are long-lasting [19]. It is not known exactly how hydroxyl radicals alter vascular function: they 
have been shown to inhibit nitric oxide synthase activity in vitro, and could react directly with nitric oxide or nitric oxide-containing nitrosothiols to neutralise their vasodilator action $[52,53]$. Moreover, hydroxyl radicals are toxic to vascular endothelium, causing cell damage or cell death $[54,55]$. The latter could explain a more general disruption of endothelial vasodilator function in diabetes, involving not only nitric oxide, but also endothelium-derived hyperpolarizing factor and prostacyclin systems [56, 57].

The marked reduction in SCG nutritive blood flow in diabetic rats probably depends on similar ROS mediated mechanisms to those for peripheral nerve, largely corrected by DMTU treatment. There is only one previous report of an SCG perfusion deficit, measurements made after at least 12 months of experimental diabetes [58]. Our data show that the ganglion blood flow deficit occurs considerably earlier than 12 months. It is possible that the impaired perfusion of neuronal cell bodies could contribute to autonomic dysfunction by restricting the energy supply for synthesis and transport of molecules essential to maintain axonal integrity and neurotransmission. Phosphocreatine concentrations in SCG were reduced in diabetic rats and this was prevented by antioxidant treatment [59]. This could be important for the relatively early occurrence of autonomic dysfunction, which affects the innervation of major organs including blood vessels, corpus cavernosum, the gastrointestinal system, and the heart [18, 33, 60-62]. For example, an oxidative stress related reduction in perfusion is thought to play a part in cardiac autonomic dysfunction, where vasodilator and antioxidant treatments improved function in diabetic rats and humans [63-65]. Similar arguments could also apply to the mechanisms of small fibre sensory neuropathy as noted in the nociception studies, because dorsal root ganglia have comparable blood flow deficits to SCG in diabetic rats [58].

In conclusion, DMTU treatment had marked effects on the deficits in small and large nerve fibre function and neural tissue perfusion in diabetic rats. The data are compatible with the notion that hydroxyl radicals contribute considerably to the mechanism of oxidative stress-mediated dysfunction. It is not possible to predict the potential effects of DMTU treatment in nerves of patients with clinical neuropathy because they have much more advanced degenerative changes than those in experimental diabetes and the degree to which this could be reversed is not known $[66,67]$. The antioxidant approach, however, has been shown to improve nerve regeneration in diabetic rats [68]. Dimethylthiourea itself might not be suitable for use in humans, having been shown to be fetotoxic in rats at a dose range (15 $100 \mathrm{mg} \cdot \mathrm{kg}^{-1} \cdot \mathrm{day}^{-1}$ ) similar to that used in these experiments [69] and to increase alveolar albumin permeability at very high doses [70]. However, given the high efficacy of DMTU compared to other more universal scavengers, it is plausible that the development of specific and potent hydroxyl radical scavengers for use in humans would greatly aid the antioxidant approach to the treatment of diabetic neuropathy and vascular disease.

Acknowledgements. This work was supported by the Juvenile Diabetes Foundation International grant 1-2000-45.

\section{References}

1. Cameron NE, Cotter MA (1999) Effects of antioxidants on nerve and vascular dysfunction in experimental diabetes. Diabetes Res Clin Pract 45: 137-146

2. Low PA, Nickander KK (1991) Oxygen free radical effects in sciatic nerve in experimental diabetes. Diabetes 40: 873-877

3. Nagamatsu M, Nickander KK, Schmelzer JD et al. (1995) Lipoic acid improves nerve blood flow, reduces oxidative stress and improves distal nerve conduction in experimental diabetic neuropathy. Diabetes Care 18: 1160-1167

4. Pieper GM (1998) Review of alterations in endothelial nitric oxide production in diabetes: protective role of arginine on endothelial dysfunction. Hypertension 31: 1047-1060

5. Cameron NE, Cotter MA, Archibald V, Dines KC, Maxfield EK (1994) Anti-oxidant and pro-oxidant effects on nerve conduction velocity, endoneurial blood flow and oxygen tension in non-diabetic and streptozotocin-diabetic rats. Diabetologia 37: 449-459

6. Cotter MA, Love A, Watt MJ, Cameron NE, Dines KC (1995) Effects of natural free radical scavengers on peripheral nerve and neurovascular function in diabetic rats. Diabetologia 38: 1285-1294

7. Love A, Cotter MA, Cameron NE (1996) Effects of the sulphydryl donor $N$-acetyl-l-cysteine on nerve conduction, perfusion, maturation and regeneration following freeze damage in diabetic rats. Eur J Clin Invest 26: 698-706

8. Sagara M, Satoh J, Wada R et al. (1996) Inhibition of development of peripheral neuropathy in streptozotocin-induced diabetic rats with n-acetylcysteine. Diabetologia 39: 263-269

9. Love A, Cotter MA, Cameron NE (1996) Nerve function and regeneration in diabetic and galactosaemic rats: antioxidant and metal chelator effects. Eur J Pharmacol 314: 33-39

10. Keegan A, Walbank H, Cotter MA, Cameron NE (1995) Chronic vitamin $\mathrm{E}$ treatment prevents defective endothelium-dependent relaxation in diabetic rat aorta. Diabetologia 38: 1475-1478

11. Archibald V, Cotter MA, Keegan A, Cameron NE (1996) Contraction and relaxation of aortas from diabetic rats: effects of chronic anti-oxidant and aminoguanidine treatments. Naunyn Schmeidebergs Arch Pharmacol 353: 584-591

12. Rösen P, Ballhausen T, Bloch W, Addicks K (1995) Endothelial relaxation is disturbed by oxidative stress in the diabetic rat heart: influence of tocopherol as antioxidant. Diabetologia 38: 1157-1168

13. Cameron NE, Cotter MA (1995) Reversal of peripheral nerve conduction and perfusion deficits by the free radical scavenger, BM15.0639, in diabetic rats. Naunyn Schmiedebergs Arch Pharmacol 352: 685-690 
14. Low PA, Nickander KK, Tritschler HJ (1997) The roles of oxidative stress and antioxidant treatment in experimental diabetic neuropathy. Diabetes 46 [Suppl 2]: S38-S42

15. Wolff SP (1995) Diabetes mellitus and free radicals. $\mathrm{Br}$ Med Bull 49: 642-652

16. Beckman JS, Beckman TW, Chen J, Marshall PA, Freeman BA (1990) Apparent hydroxyl radical production by peroxynitrite: implications for endothelial injury from nitric oxide and superoxide. Proc Natl Acad Sci USA 87: 1620-1624

17. Cameron NE, Cotter MA (1995) Neurovascular deficits in diabetic rats: potential contribution of autoxidation and free radicals examined using transition metal chelating agents J Clin Invest 96: 1159-1163

18. Keegan A, Cotter MA, Cameron NE (1999) Effects of chelator treatment on aorta and corpus cavernosum from diabetic rats. Free Radic Biol Med 27: 536-543

19. Cameron NE, Cotter MA (2001) Effects of an extracellular metal chelator on neurovascular function in diabetic rats. Diabetologia 44: 621-628

20. Qian M, Liu M, Eaton JM (1998) Transition metals bind to glycated proteins forming redox active "glycochelates": Implications for the pathogenesis of certain diabetic complications. Biochem Biophys Res Commun 250: 385-389

21. Saxena AK, Saxena P, Wu X, Obrenovich M, Weiss MF, Monnier VM (1999) Protein aging by carboxymethylation of lysines generates sites for divalent metal and redox active copper binding: Relevance to diseases of glycoxidative stress. Biochem Biophys Res Commun 260: 332-338

22. Cameron NE, Cotter MA, Hohman TC (1996) Interactions between essential fatty acid, prostanoid, polyol pathway and nitric oxide mechanisms in the neurovascular deficit of diabetic rats. Diabetologia 39: 172-182

23. Cameron NE, Cotter MA, Robertson S (1989) The effect of aldose reductase inhibition on the pattern of nerve conduction deficits in diabetic rats. Q J Exp Physiol 74: 917-926

24. Randall LO, Sellito JJ (1957) A method for measurement of analgesic activity on inflamed tissue. Arch Int Pharmacodyn Ther 111: 409-419

25. Hargreaves K, Dubner R, Brown F, Flores C, Joris J (1988) A new and sensitive method for measuring thermal nociception in cutaneous hyperalgesia. Pain 32: 77-88

26. Cameron NE, Cotter MA, Horrobin DH, Tritschler HJ (1998) Effects of $\alpha$-lipoic acid on neurovascular function in diabetic rats: interaction with essential fatty acids. Diabetologia 41: 390-399

27. Wuarin-Bierman L, Zahnd GR, Kaufmann F, Burcklen L, Adler J (1987) Hyperalgesia in spontaneous and experimental animal models of diabetic neuropathy. Diabetologia 30: 653-658

28. Courteix C, Bardin M, Massol J, Fialip J, Lavarenne J, Eschalier A (1996) Daily insulin treatment relieves longterm hyperalgesia in streptozocin diabetic rats. Neuroreport 7: 1922-1924

29. Apfel SC, Arezzo JC, Brownlee M, Federoff H, Kessler JA (1994) Nerve growth factor administration protects against diabetic sensory neuropathy. Brain Res 634: 7-12

30. Lee JH, McCarty RC (1990) Glycemic control of pain threshold in diabetic and control rats. Physiol Behav 47: 225-230

31. Delaney CA, Greene CM, Westerman RA (1995) Impaired sensory nerve function in insulin-resistant rats. In: Hotta N, Greene DA, Ward JD, Sima AAF, Boulton AJM (eds) Diabetic neuropathy: new concepts and insights. Elsevier, Amsterdam, pp 303-310

32. Cameron NE, Cotter MA, Jack AM, Basso MD, Hohman TC (1999) Protein kinase C effects on nerve function, per- fusion, $\mathrm{Na}^{+}, \mathrm{K}^{+}$-ATPase activity and glutathione content in diabetic rats. Diabetologia 42: 1120-1130

33. Nakamura J, Kato K, Hamada Y et al. (1999) A protein kinase C-beta-selective inhibitor ameliorates neural dysfunction in streptozotocin-induced diabetic rats. Diabetes 48: 2090-2095

34. Ahlgren SC, Levine JD (1994) Protein kinase C inhibitors decrease hyperalgesia and $\mathrm{C}$-fiber hyperexcitability in the streptozotocin-diabetic rat. J Neurophysiol 72: 684-692

35. Malmberg AB, Chen C, Tonegawa S, Basbaum AL (1997) Preserved acute pain and reduced neuropathic pain in mice lacking PKC gamma. Science 278: 279-283

36. Pelligrino DA, Koenig HM, Wang Q, Albrecht RF (1994) Protein kinase $\mathrm{C}$ suppresses receptor-mediated pial arteriolar relaxation in the diabetic rat. Neuroreport 5: 417-420

37. Numaguchi K, Shimokawa H, Nakaike R, Egashira K, Takeshita A (1996) PKC inhibitors prevent endothelial dysfunction after myocardial ischemia-reperfusion in rats. Am J Physiol 270: H1634-H1639

38. Xia P, Inoguchi T, Kern TS, Engerman RL, Oates PJ, King GL (1994) Characterization of the mechanism for the chronic activation of diacylglycerol-protein kinase $\mathrm{C}$ pathway in diabetes and hypergalactosemia. Diabetes 43: $1122-1129$

39. Lou MF, Dickerson JE, Garadi R, York BM (1988) Glutathione depletion in the lens of galactosemic and diabetic rats. Exp Eye Res 46: 517-530

40. Cameron NE, Cotter MA (1993) Contraction and relaxation of aortas from galactosaemic rats and the effects of aldose reductase inhibition. Eur J Pharmacol 243: 47-53

41. Ziegler D, Hanefeld M, Ruhnau KJ (1995) Treatment of symptomatic diabetic peripheral neuropathy with the antioxidant (-lipoic acid. A 3-week multicentre randomized controlled trial (ALADIN Study). Diabetologia 38: 1425-1433

42. Jarvis MF, Wessale JL, Zhu CZ et al. (2000) ABT-627, an endothelin $\mathrm{ET}_{\mathrm{A}}$ receptor-selective antagonist, attenuates tactile allodynia in a diabetic rat model of neuropathic pain. Eur J Pharmacol 388: 29-35

43. Cameron NE, Dines KC, Cotter MA (1994) The potential contribution of endothelin-1 to neurovascular abnormalities in streptozotocin-diabetic rats. Diabetologia 37: 1209-1215

44. Pieper GM, Siebeneich W, Roza AM, Jordan M, Adams MB (1996) Chronic treatment in vivo with dimethylthiourea, a hydroxyl radical scavenger, prevents diabetes-induced endothelial dysfunction. J Cardiovasc Pharmacol 28: 741-745

45. Mayhan WG, Patel KP (1998) Treatment with dimethylthiourea prevents impaired dilatation of the basilar artery during diabetes mellitus. Am J Physiol 274: H1895H1901

46. Pieper GM, Siebeneich W (1997) Diabetes-induced endothelial dysfunction is prevented by long term treatment with the modified iron chelator, hydroxyethyl starch conjugated-deferoxamine. J Cardiovasc Pharmacol 30: 734-738

47. Kihara M, Low PA (1995) Impaired vasoreactivity to nitric oxide in experimental diabetic neuropathy. Exp Neurol 132: $180-185$

48. Maxfield EK, Cameron NE, Cotter MA (1997) Effects of diabetes on reactivity of sciatic vasa nervorum in rats. J Diabetes Complications 11: 47-55

49. Drummond GR, Cai H, Davis ME, Ramasamy S, Harrison DG (2000) Transcriptional and posttranslational regulation of endothelial nitric oxide synthase expression by hydrogen peroxide. Circ Res 86: 347-354 
50. Yang Z, Zhang A, Altura BT, Altura BM (1999) Hydrogen peroxide-induced endothelium-dependent relaxation of rat aorta involvement of $\mathrm{Ca}^{2+}$ and other cellular metabolites. Gen Pharmacol 33: 325-336

51. Karasu C (2000) Time course of changes in endotheliumdependent and -independent relaxation of chronically diabetic aorta: role of reactive oxygen species. Eur J Pharmacol 392: 163-173

52. Xu KY (2000) Nitric oxide protects nitric oxide synthase function from hydroxyl radical-induced inhibition. Biochim Biophys Acta 1481: 156-166

53. Marshall JJ, Wei EP, Kontos HA (1988) Independent blockade of cerebral vasodilation from acetylcholine and nitric oxide. Am J Physiol 255: H847-H854

54. Morel DW, Chisolm G (1989) Antioxidant treatment of diabetic rats inhibits lipoprotein oxidation and cytotoxicity. J Lipid Res 30: 1827-1834

55. Az-ma T, Fujii K, Yuge O (1996) Self-limiting enhancement by nitric oxide of oxygen free radical-induced endothelial cell injury: evidence against the dual action of $\mathrm{NO}$ as a hydroxyl radical donor/scavenger. $\mathrm{Br} \mathrm{J}$ Pharmacol 119: 455-462

56. Keegan A, Jack AM, Cameron NE, Cotter MA (2000) Effects of aldose reductase inhibition on responses of the corpus cavernosum and mesenteric vascular bed of diabetic rats. J Cardiovasc Pharmacol 35: 606-613

57. Ward KK, Low PA, Schmelzer JD, Zochodne DW (1989) Prostacyclin and noradrenaline in peripheral nerve of chronic experimental diabetes in rats. Brain 112: 197-208

58. Sasaki H, Schmelzer JD, Zollman PJ, Low PA (1997) Neuropathology and blood flow of nerve, spinal roots and dorsal root ganglia in longstanding diabetic rats. Acta Neuropathol (Berl) 93: 118-128

59. Kishi Y, Schmelzer JD, Yao JK et al. (1999) $\alpha$-Lipoic acid: effect on glucose uptake, sorbitol pathway and energy metabolism in experimental diabetic neuropathy. Diabetes 48: 2045-2051

60. Kurata C, Okayama K, Wakabayashi Y et al. (1997) Cardiac sympathetic neuropathy and effects of aldose reductase inhibitor in streptozotocin-induced diabetic rats. J Nucl Med 38: 1677-1680

61. Jenkinson KM, Reid JJ (1995) Effect of diabetes on relaxations to non-adrenergic, non-cholinergic nerve stimulation in longitudinal muscle of the rat gastric fundus. $\mathrm{Br} \mathrm{J}$ Pharmacol 116: 1551-1556

62. Ralevic V, Belai A, Burnstock G (1995) Effects of streptozotocin-diabetes on sympathetic nerve, endothelial and smooth muscle function in the rat mesenteric arterial bed. Eur J Pharmacol 286: 193-199

63. Hotta N, Koh N, Sakakibara F et al. (1996) Effects of beraprost sodium and insulin on the electroretinogram, nerve conduction and nerve blood flow in rats with streptozotocin-induced diabetes. Diabetes 45: 361-366

64. Kontopoulos AG, Athyros VG, Didangelos TP et al. (1997) Effect of chronic quinapril administration on heart rate variability in patients with diabetic autonomic neuropathy. Diabetes Care 20: 355-361

65. Ziegler D, Schatz H, Gries FA, Ulrich H, Reichel G (1997) Effects of treatment with the antioxidant $\alpha$-lipoic acid on cardiac autonomic neuropathy in NIDDM patients. A 4month randomized controlled multicenter trial (DEKAN Study). Diabetes Care 20: 369-373

66. Tesfaye S, Malik R, Ward JD (1994) Vascular factors in diabetic neuropathy. Diabetologia 37: 847-854

67. Cameron NE, Cotter MA (2000) New therapeutic approaches to prevent or halt the progression of the longterm complications of diabetes mellitus: focus on neuropathy. Curr Opin Oncol 2: 162-177

68. Love A, Cotter MA, Cameron NE (1997) Effects of $\alpha$-tocopherol on nerve conduction velocity and regeneration following a freeze lesion in immature diabetic rats. Naunyn Schmeidebergs Arch Pharmacol 355: 126-130

69. Saillenfait AM, Sabate JP, Langonne I, de Ceaurriz J (1991) Differences in the developmental toxicity of ethylenethiourea and three N, N'-substituted thiourea derivatives in rats. Fundam Appl Toxicol 17: 399-408

70. Beehler CJ, Ely ME, Rutledge KS et al. (1994) Toxic effects of dimethylthiourea in rats. J Lab Clin Med 123: 73-80 